\title{
Struktura reciproke me emra valentë
}

\author{
Emine Sadiku
}

-Ilustruar me material nga proza e një autori elbasanas-

\section{Dy fjalë për autorin e tregimeve}

Në punimin që vijon do të bëhet fjalë për një dukuri gjuhësore jo shumë të trajtuar në studimet shqiptare. Mendimet dhe paraqitjet teorike do të ilustrohen me material gjuhësor të marrë nga proza e një autori interesant nga Elbasani. Për më tepër, proza e tij trajton e përshkruan jetën që rrjedh mjediseve të qytetit Elbasan e të disa trevave rurale rreth tij. Autori quhet Safet Sadiku. Për lexuesin elbasanas e më gjerë Safet Sadiku është i njohur nëpërmjet shkrimeve të shumtë në gazetën “Shkumbini”. Përmbi 20 vjet ai debutoi me sukses në këtë organ duke provuar të gjitha zhanret e publicistikës, si artikujt problemorë, ata informativë, kritikën letrare etj.

Për një kohë shumë të gjatë shërbeu si mësues në zona të thella të vendit, më gjatë në krahinën e Shpatit. Përvoja në gazetë dhe në detyrën e nderuar të mësuesit e ka nxitur të qëmtojë ngjarje dhe episode nga jeta e përditshme, t’i trajojë ato me pjekuri krijuese në librat e tij artistikë. Safeti, si njohës i thellë i karakterit të shpatarakut, ka depërtuar në botën e tij të brendshme dhe që andej është përpjekur të nxjerrë në pah vlerat universale të banorëve të kësaj treve të nderuar. (Shih dhe: Pupuleku, M.: Parathënie e vëllimit "Tregimet e Shpatit", Elbasan, 2006, f.3)

Proza e këtij autori ka bërë objekt letrar edhe shumë aspekte nga jeta në qytetin sa të lashtë, aq dhe modern të Elbasanit. Figurat e tij, personazhet, që gjëllijnë në prozën e botuar të këtij autori, janë njerëz me veçori të spikatura, pozitive ose negative. Një pjesë e mirë e episodeve janë ngjarje të periudhës famëkeqe të tranzicionit shqiptar. Figurave u duhet të ndeshen e të luftojnë 


\section{Albanon}

\section{Revistë kulturore}

me gjithëfarë dukurish të shëmtuara. Edhe kur mbijetojnë janë veç viktima që kanë humbur pothuaj gjithçka. Në asgjënë përfundon vrapi i tyre drejt lumturisë.

Në pikëpamje të një korpusi empirik për punimin tim (në fazën e tanishme), proza e autorit në fjalë m’u paraqit si një domen i begatë, si një "minierë" ilustrimesh për teorizimet e mia, me larmi formale e përdorimore ku zunë fill e morën udhë mendime të reja, shtesa ndaj teorive të njohura më parë.

\begin{tabular}{|c|c|}
\hline $\begin{array}{l}\text { Shënim } \\
\text { paraprak }\end{array}$ & $\begin{array}{l}\text { Sa herë që bie fjala për valencën, mendja të shkon, së pari tek } \\
\text { ajo foljore, pastaj tek ajo mbiemërore. Për një kohë të gjatë, } \\
\text { valenca emërore nuk kishte statusin e saj të veçantë si dukuri } \\
\text { ekzistente, me tiparet karakteristike të kësaj kategorie semantike } \\
\text { e morfosintaksore. Por pas botimit të "Wörterbuch zur Valenz } \\
\text { und Distribution der Substantive" (Sommerfeld/ Schreiber, 1977), } \\
\text { si dhe të studimit të Teubert ( Valenz des Substantivs, 1979), u } \\
\text { provua që edhe emrat kanë valencë. Tashmë kemi një literaturë } \\
\text { të bollshme, ku gjëllijnë dhe konkurrojnë shumë teori e drejtime } \\
\text { mbi valencën e emrit. Gramatika e varësisë dhe e valencave } \\
\text { përbën një fushë të rëndësishme studimi në kuadrin e gjuhësisë } \\
\text { strukturaliste. Por në këtë domen ka ende shumë pyetje dhe } \\
\text { çështje që kërkojnë përgjigje dhe analiza. Një nga këto çështje } \\
\text { është ajo e strukturave reciproke të emrave valentë. }\end{array}$ \\
\hline
\end{tabular}

\section{Rëndësia e një studimi të tillë}

Në letërsinë gjuhësore shqiptare vërehet mungesë studimesh të kësaj kategorie, mungojnë analizat e thelluara në këtë fushë. Për këtë, punimi ynë do të kontribuojë në mbushjen e një boshllëku në teorinë e valencës emërore.

Studimi i strukturave reciproke me përfundimet përkatëse do të ndihmonte në hartimin dhe paraqitjen më të mirë të valencës së emrave në fjalorët $\mathrm{e}$ tipave të ndryshëm.

Në mësimin e gjuhës së huaj përfitimi është i padiskutueshëm. Përshkrimi i saktë i strukturës argumentative ka rëndësi, jo vetëm për foljen, por edhe për emrin. Sot preferohet mësimi i gjuhës së huaj me sintagma dhe jo me fjalë të veçuara. 


\section{Grupe emrash valentë}

Në klasën e emrave që shfaqin valencë, do të përfshijmë:

- Emra prejfoljorë: ata e trashëgojnë valencën nga bazat - foljore prej të cilave rrjedhin.

Në këtë grup do të përfshinim disa nëngrupe:

- Emra veprimi:

shpërblej sakrificën $\longrightarrow$ shpërblim i sakrificës; punoj tokën ${ }^{\oplus}$ punimi i Tokës;

- Emra që shënojnë gjendje: zhgënjej nënёn $\rightarrow$ zhgënjimi i nënës; zemëroj shokët zemërimi i shokëve;

- Emra që shënojnë proces: rris vajzën $\rightarrow$ rritja e vajzës;

- Emërtime rezultati: Kolombi zbuloi Amerikën $\longrightarrow$ zbulimi i Amerikës nga Kolombi;

- Emërtime vepruesish: marr pjesë në lojë $\rightarrow$ pjesëmarrës në lojë.

Shënim: Nuk do të merremi me një analizë të mëtejshme të dukurisë e të elementeve të nëngrupeve të dalluara pak më sipër, sepse nuk është qëllim i këtij punimi. E njëjta gjë vlen dhe për grupimet e mëposhtme.

- Emra mbiemërorë: edhe këta bartin valencën e mbiemrit nga kanë rrjedhur: e ka shpirtin të pastër $\rightarrow$ pastërtia e shpirtit; bursë e refuzuar $\rightarrow$ refuzim i bursës.

- Emra relacionalë: janë një grup emrash që kanë valencë origjinale, të pakushtëzuar nga njësi të tjera gjuhësore. Termi "relacional” përdoret në një kuptim të gjerë dhe në një të ngushtë. Në kuptimin e gjerë relacionalë do të ishin të gjithë ata emra që nuk mund të përdoren në ligjërim pa u lidhur me njësi të tjera plotësuese, që hapin vende bosh, të cilat plotësohen me elemente të tjera të domosdoshme. Ky term ka dhe një kuptim të ngushtë: shënon vetëm klasën e emrave me valencë origjinale (Shih: Fedorovna, Anna: Relationale Substantive, Münich, 2004)

Në këtë kuptim do ta përdorim edhe ne, meqë specifikimi i grupeve bëhet më thjesht dhe më mirë.

Në pikëpamje semantike ky grup përfshin: 


\section{Albanon}

Revistë kulturore

- Emërtime të lidhjeve familjare e farefisnore: $b a b a, x h a x h a, v e ̈ l l a$, nёnё;

- Emërtime pjesësh të një së tëre: një e treta, gjysma, shumica;

- Emra që shënojnë pjesë të trupit: kokë, qafé, hundë;

- Emra që shënojnë bashkësi, grupe: tufé, hordhi, lukuni;

- Emra që shënojnë pika ndodhjeje në hapësirë: majë, fund, mes.

- Emra reciprokë, emra me kuptim reciprok: ky është grupi me të cilin do të merremi në vijim. Këtë element gjuhësor, emrin valent me kuptim reciprok, do ta shohim dhe si përbërës të strukturave të caktuara. Në këto struktura, emri përbën fjalën bosht në pikëpamje strukturore dhe kuptimore. Ata drejtojnë parafjalët dhe argumentet e grupit.

Duhet thënë që në fillim që ky është një grup heterogjen. Në të përfshihen:

- emra prejfoljorë:

grindje, përballje, lidhje, zhgënjim, ndarje, përqafim, dëbim;

- emra prejmbiemërorë:

dashuri, xhelozi, hasmëri, besnikëri, ngjashmëri;

- Emra me valencë vetiake:

mall, mëri, martesë, frikë, fejesë, bisedë, dialog.

- Një nëngrup të gjerë përbëjnë emrat kompozita:

hakmarrje, bashkëshort, bashkëbisedues, marrëdhënie, bashkëvuajtje, bashkëjetesë etj.

\section{Veçori semantike dhe morfosintaksore të emrave reciprokë}

Emrat me kuptim reciprok formojnë një klasë me semantikë të veçantë ku ekzemplarët janë, së paku, dyvalentë. Ata përcaktojnë sasinë, cilësinë, rasën dhe parafjalët e argumenteve të tyre. Për përkufizimin, dallimin dhe trajtimin teoriko-pragmatik të emrave reciprokë ne jemi mbështetur, së pari, në semantikën e tyre. Në vëllimin kuptimor të elementeve të tilla komponenti "reciprok" është gjithnjë i pranishëm. Fjalori i gjuhës shqipe (Tiranë, 1984, f. 1012) jep këtë formulim për përmbajtjen e njësisë leksikore "reciprok":

1. indërsjellë, i dyanshëm;

2. që bënte shkëmbimin e prodhimeve bujqësore me prodhime industriale.

Në rastin tonë është me interes kuptimi i parë. Fjalët e qëmtuara prej nesh, të dalluara si emra reciprokë, përmbajnë të githa tiparin e reciprocitetit, janë emërtime veprimesh, aktesh, gjendjesh, ndjenjash etj. që nënkuptojnë 
e shprehin momente të ndërsjella. Në një analizë të thjeshtë të semantikës së tyre spikat menjëherë komponenti "reciprok": dy madhësi veprojnë në mënyrë të ndërsjellë për të krijuar një situatë. Shenjimi, kuptimi i tyre referon në një realitet ku ka bashkëveprim, bashkëndikim, reagim të ndërsjellë. Ja disa shembuj:

Muhabeti rridhte lirshëm dhe pa ndihmën e rakisë. (Muhabet me një aktant nuk mund të ketë). (Sadiku, S.: "Dy orë nga jeta e Selimit", 2014, f. 4);

Por edhe në marrëdhëniet me Balin filluan krizat e para. (Sadiku, S.: "Dy orë nga jeta e Selimit", 2014, f. 100);

Tërheqja prej saj do të qe një disfatë e pariparueshme. (Sadiku, S.: "Dy orë nga jeta e Selimit”, 2014, f. 101);

Nuk kam qenë sëmurë, por pata një takim tjetër. (Sadiku, S.: "Dy orë nga jeta e Selimit", 2014, f. 100);

Erdhi dhe një tjetër shkëputje e gjatë. (Sadiku, S.: "Dy orë nga jeta e Selimit", 2014, f. 103);

Etj.

Një emër i klasifikuar si reciprok nuk mund të qëndrojë vetëm në fjali. Në një strukturë minimale me vlerë fjalie nuk hasim emra me kuptim reciprokë të pashoqëruar me elemente gjuhësore plotësuese. Kjo ndodh vetëm kur përdoren si njësi absolute, jo relacionale ose në kontekste (eliptike) ku nënkuptohet plotësori i emrit reciprok:

Ajo shkatërron dhe të ashtuquajturën dashuri. (Sadiku, S.: "Tregimet e Shpatit”, 2006, f. 24)

Emrat reciprokë e shpalosin natyrën e tyre të plotë brenda strukturave reciproke. Një strukturë reciproke përmban: emra valentë me kuptim reciprok (që shënojnë raporte të ndërsjella); parafjalë të caktuara dhe së paku dy aktantë. Më sipër theksuam që emrat reciprokë janë të paktën dyvalentë. Lidhur me valencën duhet të dallojmë atë potenciale dhe atë të realizuar. Në rastin:

Por ka ca gjëra të lavdërueshme, siç është respekti i tij për të tjerët. (Sadiku, S.: "Dy orë nga jeta e Selimit", 2014, f. 117).

Të dy argumentet janë dhënë eksplicite: $e$ tij; për të tjerët. 


\section{Albanon}

\section{Revistë kulturore}

Në rastin tjetër:

Ankthi kishte filluar që pas njohjes me të. (Sadiku, S.: "Dy orë nga jeta e Selimit”, 2014, f.100).

Kemi të shprehur vetëm njërin argument me të. Argumenti tjetër i mundshëm së tij nuk realizohet. Bëhet fjalë për një argument implicit. Në materialin e vjelë nga të dy vëllimet me tregime të autorit, S. Sadiku, strukturat reciproke rrallëherë i kanë të shprehur të dy argumentet:

Kjo alternativë e vetme na u paraqit në takimin tim të parëme të. (Sadiku, S.: "Tregimet e Shpatit", 2006, f. 100).

Zakonisht emrat reciprokë në tekst nuk i zhvillojnë komplet valencat e tyre. Kjo nuk sjell boshllëqe kuptimore, konteksti ndihmon në plotësimin e strukturës argumentore të ndërtimeve reciproke:

Nuk isha e sigurtë nëse ai do t’i gëlltiste këto aventura për të pranuar bashkëjetesën. (Sadiku, S.: "Dy orë nga jeta e Selimit", 20014, f. 94).

Eksplicit nuk jepet asnjë argument. Por në kontekst bëhen të qarta dy argumentet e mundshme: time, me të. Madje, në rastin e emrit, bashkëjetesën, do të mjaftonte vetëm njëri argument për ta plotësuar strukturën reciproke: me mua. Argumenti tjetër $e$ tij është i tepërt, gjuhësisht i panevojshëm. Ose në rastin:

Qeshë ngatërruar më shumë, edhe gjatë kohës pas njohjes me të (Sadiku, S.: "Dy orë nga jeta e Selimit", 2014, f. 95).

Mund të realizohej edhe argumenti sime (pas njohjes sime me të). Mungesa e tij nuk sjell ndonjë pështjellim në të kuptuarin e fjalisë brenda ose jashtë kontekstit. Tregues i vetës së parë, që jep ligjëruesin, është dhe forma foljore "qeshë".

Emri reciprok, si bartës valence, përbën njësinë bazë të frazës nominale ku merr pjesë. Dy argumentet (A1, A2) përcaktohen nga struktura semantike e emrit, emri hap dy vende për plotësit e tij. Po në pikëpamje semantike emrat valentë reciprokë mund t'í grupojmë në fusha kuptimore. Ne jemi mbështetur për këtë organizim në teorinë e Teubert (Teubert, Wolfgang: Substantivvalenz, 1979, unveröffentlichtes Manuskript).

Sipas veçorive më të përgjithshme semantike të emrave reciprokë dallohen këto fusha:

- Veprimtari dhe raporte midis njerëzish: miqësi, bisedë, martesë, zënkë;

- Raporte reciproke: tregti, bashkëpunim, bashkëbisedim, kontratë;

- Ndarje: largim, mospajtim, mosnjohje, dallim; 
- Veprim kolektiv: protestë, lojë;

- Ngjashmëri dhe jongjashmëri: ngjashmëri, ndryshim.

(Shih dhe: Teubert, Wolfgang (1999): Substantivvalenz. Unveröffentlichtes Manuskript)

\section{Tipare morfosintaksore të emrave reciprokë}

Në pikëpamje të ndërtimit morfologjik emrat reciprokë mund të jenë:

- të thjeshtë (të parmë): mall, bisedë, lojë;

- të prejardhur ( prejfoljorë dhe prejmbiemërorë): grindje, takim, miqësi, dashuri;

- kompozita: marrëveshje, marrëdhënie, pjesëmarrje.

Numrin më të madhe të njësive të qëmtuara nga ne e përbëjnë formimet prejfoljore. Vlen gjithashtu të vihet në dukje që shumë kompozita dalin me një kokë foljore. Nga hetimet tona rezulton se morfologjia e emrave valentë reciprokë ndikon shumë pak në strukturën e tyre argumentore. Emrat e parmë reciprokë janë më homogjenë edhe se emrat e prejardhur prejfoljorë në ndërtimet e tyre reciproke. Emrat valentë, që shfaqen vetëm në strukturat reciproke, me një gradë të lartë reciprociteti (100\%), janë quajtur "reciprokë leksikorë": duel, zënkë, lojë, mall, krahasim... Ata mund të jenë të parmë ose të prejardhur.

\section{Tipare morfosintaksore të parafjalëve në strukturat reciproke}

Në korpusin tonë, me tregime të autorit $S$. Sadiku, kemi evidentuar këto parafjalë që marrin pjesë në ndërtimet reciproke: prej, me, për, në, midis, mes, kundër, ndaj, nga, përtej .....

Aq herë ndryshonin edhe joshjet prej tij. (Sadiku, S.: "Tregimet e Shpatit", 2006, f. 93).

Mbushur me dashuri për kohë më të mira. (Sadiku, S.: "Tregimet e Shpatit", 2006, f. 57).

Ai vuante nga malli për vendin e tij të largët. (Sadiku, S.: "Tregimet e Shpatit”, 2006, f. 75). 


\section{Albanon}

\section{Revistë kulturore}

Pati njëfarë ngrohjeje në marrëdhëniet me Astritin. (Sadiku, S.: "Dy orë nga jeta e Selimit”, 2014, f. 100).

Përballja me të mund të na hapë punë. Shpati, (Sadiku, S.: "Tregimet e Shpatit", 2006, f. 75).

E kisha pothuaj të pamundur artin e përshtatjes ndaj konjunkturave. (Sadiku, S.: "Tregimet e Shpatit", 2006, f. 96).

Ardhja ime këtu është një shfajësim dhe dëmshpërblim ndaj teje. (Sadiku, S.: "Tregimet e Shpatit", 2006, f. 77).

Edhe herë të tjera patën lindur zënka mes nesh. (Sadiku, S.: "Tregimet e Shpatit", 2006, f. 98).

A ka lidhje mes tyre? (Sadiku, S.: "Tregimet e Shpatit", 2006, f. 28).

Largimi nga puna na vinte në vështirësi të mëdha. (Sadiku, S.: "Tregimet $\mathrm{e}$ Shpatit", 2006, f. 32).

Fillova të fantazoj biseda përtej çdo realiteti. (Sadiku, S.: "Tregimet e Shpatit", 2006, f. 89).

Ndarja prej saj e kishte rrënuar pa shpresë. (Sadiku, S.: "Tregimet e Shpatit", 2006, f. 74).

Lexoi tregimin e shkruar nën pushtetin e dashurisëpër të. (Sadiku, S.: "Tregimet e Shpatit", 2006, f. 100).

Distanca midis nesh ishte zgavruar. (Sadiku, S.: "Tregimet e Shpatit", 2006, f. 100).

Sharjet kundër pushtetit tani bëheshin hapur. (Sadiku, S.: "Dy orë nga jeta e Selimit”, 2014, f. 101).

Parafjalët e përdorura në sintagmat reciproke janë kryesisht të parme. Ato qëndrojnë pas emrit me kuptim reciprok dhe formojnënjëlidhjeidiosinkratike me të. Në rastin e përdorimit të parafalëve në strukturat reciproke, njësia "parafjalë" shikohet kryesisht në bashkëlidhje me emrin reciprok, e drejtuar prej tij dhe jo si drejtuese/përcaktuese e rasës së njësisë pasardhëse. Parafjalët nuk kanë kuptim të pavarur, ato e shfaqin kuptimin dhe funksionin e tyre në kontekst. Janë fjalë sinsemantike dhe jo autosemantike (me kuptim të pavarur). Por mund të flitet për një kuptim bazë, një lloj gramatikalizimi, që shfaqet (pothuaj) në çdo përdorim të tyre. P.sh.: parafjala kundër "përdoret me një emër, përemër a numëror në rasën rrjedhore, për të treguar drejtimin e kundërt me lëvizjen e dikujt a të diçkaje, vendin përballë dikujt a diçkaje ose dikë a diçka që e luftojmë a na dëmton.” (Fjalori i Shqipes së Sotme, Tiranë, 
1984, f. 570). Edhe në bashkëvajtje me një emër reciprok në tekstin tonë, kjo parafjalë e ruan kuptimin e kundërtisë:

luftë kundër; lojë kundër; betejë kundër; përpjekje kundër...

\section{Shembuj me fjali:}

Sulmet kundër meje sapo kishin filluar. (Sadiku, S.: Tregimet e Shpatit, 2006, f. 66).

Nuk munda t'u shmangesha bisedave kundër nesh. (Sadiku, S.: Tregimet e Shpatit, 2006, f. 83).

Veprimi kundër urdhrit më kushtoi shumë. (Sadiku, S.: Tregimet e Shpatit, 2006, f. 93).

Në strukturat reciproke, parafjala kundër shpreh kundërshti, qëndresë. Në kuptimin e saj ndikon ndjeshëm dhe kuptimi kryesor i emrit drejtues.

Parafjalët e qëmtuara nga ne në korpusin e cituar, janë zakonisht të parme dhe drejtohen nga emrat pararendës. Nga njëra anë ato janë të kushtëzuara nga emri para tyre, nga ana tjetër shërbejnë si kokë e frazave parafjalore. Në bashkimin emër - parafjalë, emri është përcaktues- drejtues. Për nga pozicioni ato qëndrojnë direkt pas emrit drejtues ose pas një atributi në gjinore. Parafjalët e shqyrtuara drejtojnë rasa të caktuara: emërore, kallëzore ose rrjedhore. Parafjalët më të përdorshme në strukturat reciproke të hetuara nga ne janë me, për.

\section{Tipare morfosintaksore dhe semantike të argumenteve}

Po i referohemi së pari klasifikimit të Teubert ( 1979, f. 88). Ai dallon 17 klasa plotësish prejemërorë që qëndrojnë në lidhje me 12 klasa emrash drejtues. Nga klasat e plotësave të dalluara nga Teubert, klasat e mëposhtme kanë të bëjnë me strukturat reciproke :

\begin{tabular}{|l|l|l|l|}
\hline Lloji i plotësit & Lloji i emrit drejtues & Realizimi & Shembuj \\
\hline Plotës agjenti & Emër veprimi & $\begin{array}{l}\text { Frazë emërore me një } \\
\text { formë gjinore në përbërje } \\
\text { Frazë emërore me një } \\
\text { formë gjinore në përbërje }\end{array}$ & Lufta e shpatarakëve \\
& Emër rezultati & Vendimi i Prenit \\
\hline
\end{tabular}




\begin{tabular}{|l|l|l|l|}
\hline Lloji i plotësit & Lloji i emrit drejtues & Realizimi & Shembuj \\
\hline Plotës i & Emër veprimi & me/midis + frazë & Lufta me kundërshtarin \\
pjesëmarrjes & & nominale & Ballafaqimi me Agimin (me \\
& Emër procesi & $\begin{array}{l}\text { me/midis + frazë nominale } \\
\text { të) }\end{array}$ & Köremërore) \\
& Emër rezultati & me/midis + frazë & nominale \\
& Emër gjendjeje & me/midis + frazë nominale & Martesa e tij me Evën \\
& & \\
& &
\end{tabular}

Plotësat e agjentit shënojnë persona ose institucione (shumë rrallë kafshë). Këta varen nga klasa e emrave që shënojnë veprime ose rezultate. Kjo klasë plotësish i korrespondon gjinores subjektive (kryefjalore). Plotësat agjentivë realizohen nga një grup emër + emër/përemër në gjinore.

Plotësat e pjesëmarrjes shënojnë pjesëmarrësin ose pjesëmarrësit në gjendjen faktike të shprehur nga emri drejtues. Madhësia e shënuar nga emri drejtues mund të jetë një veprim, një proces ose një gjendje që kërkojnë gjithnjë dy pjesëmarrës. Të dy pjesëmarrësit në veprim mund të shprehen me një plotës agjenti: Grindja e Astritit dhe e Balit.

Plotësi agjentiv mund të shënojë vetëm një veprues, vepruesi tjetër jepet me një plotës të pjesëmarrjes: E shqetësonte dhe lajmi $i$ martesës së Lilianës me plakun e pasur.

Të dy pjesëmarrësit në veprim shprehen me një plotës pjesëmarrjeje: Grindja midis Astritit dhe Balit.

Argumentet e strukturave reciproke me veçoritë e tyre semantike dhe morfosintaksore janë po aq të rëndësishme sa elementet e tjera të këtyre strukturave në përftimin e reciprocitetit. Argumentet me specifikat e tyre ankorohen në strukturën kuptimore të emrit drejtues. Kjo do të thotë që rasa dhe statusi parafjalor i argumentit përcaktohet nga emri drejtues. Argumentet mund të jenë atribute në gjinore (gjinore subjektive, gjinore objektive, gjinore posesive).

Argumentet mund të shprehen dhe me fraza parafjalore e me fjali.

\section{Disa tipa strukturorë të argumenteve në segmentet reciproke}

Në letërsinë e përdorur si korpus studimi në këtë punim, tipi më i përdorur është ai me një argument të realizuar. Ky mund të jetë gjymtyra në gjinore ose ajo me parafjalë: 
Të numërosh orët deri në takimin e mbrëmjes... (Sadiku, S.: "Tregimet e Shpatit", 2006, f. 82).

Realizohet vetëm atributi i shprehur me gjinore. Mund të jepej dhe një gjymtyrë tjetër- plotës me parafjalë me të, me Lilianën.

Përballja me të mund të na hapte punë. (Sadiku, S.: "Tregimet e Shpatit", 2006, f. 74).

Realizohet vetëm plotësi me parafjalë, mbetet fakultativ plotësi në gjinore (ose i shprehur me një pronor) e grupit tonë ose jonë.

Disa struktura të tjera argumentore që shfaqen shpesh në tekst janë:

Formë në gjinore + plotës me parafjalën me:

Ndarja e Astritit me Teutën na erdhi papritur. (Sadiku, S.: "Tregimet e Shpatit", 2006, f. 20).

Formë në gjinore + plotës me parafalën prej:

Shmangia e shokëve të tij të dikurshëm prej tij fliste shumë. (Sadiku, S.: "Dy orë nga jeta e Selimit", 2014, f. 71).

Formë në gjinore + plotës me parafjalën për:

Vetë isha i befasuar nga dashuria e Balit për të. (Sadiku, S.: "Dy orë nga jeta e Selimit”, 2014, f. 121).

Formë në gjinore + plotës me parafjalën me/ndaj:

Por unë nuk kam arritur ta justifikoj dashurinë e Maries për Mazepën; të Robinjës ndaj Khanit.

(Sadiku, S.: "Dy orë nga jeta e Selimit", 2014, f. 24).

\section{Dezintegrimi dhe integrimi i emrave valentë reciprokë}

Siç kemi thënë, emrat valentë të strukturave reciproke, zakonisht i shfaqin veçoritë e tyre brenda lidhjesh të caktuara. Argumentet, që kërkojnë ata, shprehen me mjete morfosintaksore. Në kontekste të ndryshme ndodh edhe dezintegrimi i tyre nga strukturat reciproke. Edhe pse e nënkuptojnë reprocitetin në semantikën e tyre, ata shfaqen të vetëm si njësi jo më relacionale, por absolute. Kjo ndodh kur nuk është nevoja për hapje vendesh bosh nga emrat që përndryshe shprehin marrëdhënie reciproke:

Por jeta ka dhe ndarje. (Sadiku, S.: Tregimet e Shpatit, 2006, f. 18).

Është mallkim të braktisësh vendin tënd. (Sadiku, S.: Tregimet e Shpatit, 2006, f. 14). 


\section{Albanon}

\section{Revistë kulturore}

Qe e kotë çdo përpjekje për ta nxjerrë nga uji. (Sadiku, S.: Tregimet e Shpatit, 2006, f. 10).

Është puna ime kur i bëj takimet. (Sadiku, S.: Dy orë nga jeta e Selimit, 2014, f. 98).

... imazh në të cilin mungojnë tradhëtitë dhe pabesitë. (Sadiku, S.: Dy orë nga jeta e Selimit, 2014, f. 107).

Në këto shembuj, emrat ndarje, malli, përpjekje, takimet, tradhëtitë, pabesitë, që përmbajnë komponentin reciprocitet në përmbajtjen e tyre, përdoren si absolutë. Këtu nuk është nevoja e hapjes së vendeve bosh, njësitë e nënvizuara shfaqen vetëm në kuptimin e tyre abstrakt. Nuk kemi referencë konkrete në realitet.

Në disa raste, plotësimi i vendeve bosh nuk bëhet direkt, por në mënyrë latente:

Kështu më dukeshin mua ajo ndarje, ai shkallëzim...(Sadiku, S.: Tregimet e Shpatit, 2006, f. 21).

Të ndjesh në këtë ndjekje thirrjen e shokut të dikurshëm. (Sadiku, S.: Tregimet e Shpatit, 2006, f. 84).

Epo më shumë se miqësia një tjetër hall më ka sjellë sot te ty. (Sadiku, S.: Tregimet e Shpatit, 2006, f. 61).

Më çuan në një repart ndjekjeje, ku ishim gjithnjë me kokë në torbë. (Sadiku, S.: Tregimet e Shpatit, 2006, f. 66).

Ti simë ke kërkuar asgjë veç këtyre takimeve. (Sadiku, S.: Dy orë nga jeta e Selimit, 2014, f. 88).

Pak e dinë se ne kemi marrëdhënie. (Sadiku, S.: Dy orë nga jeta e Selimit, 2014, f. 88).

Ky mospajtim nuk duhej thelluar më tej. (Sadiku, S.: Dy orë nga jeta e Selimit, 2014, f. 88).

Megjithatë është e diskutueshme, nëse në raste të tilla mund të flitet për dezintegrim. Përdorime të tilla lindin në kontekste ku qartësohet natyra reciproke e emrit. Kështu që mungesa e plotësit të domosdoshëm nuk është gjithnjë shenjë e dezintegrimit nga strukturat reciproke. Prandaj do të thonim se më shumë se dezintegrim kemi përdorim absolut të emrave që shënojnë reciprocitet.

Ndodh edhe që një emri, që nuk mund të bëjë pjesë në strukturat reciproke, në kontekst t’i atashohet kuptim reciprok: 
E pati dhe puna jonë sot. (Sadiku, S.: Tregimet e Shpatit, 2006, f. 55).

Emri puna është absolut, por në togun puna jonë shfaq veti reciproke. Kjo dukuri është e kundërta e dezintegrimit, e zhveshjes nga komponenti kuptimor reciprok. Një element, një emër, që nuk e përmban reciprocitetin në strukturën e tij kuptimore, e fiton atë në kontekst. Kjo ndodh me shtimin e një shenje tjetër, në rastin tonë të një posesivi (veta I, shumës). Me anë të këtij procesi lindin zakonisht komplekse shenjore dhe jo shenja/fjalë të veçanta:

Kjo ishte në interesin tonë tëpërbashkët. (Sadiku, S.: Tregimet e Shpatit, 2006, f. 70).

\section{Përfundime}

Punimi i paraqitur prej nesh, siç mund të shihet, është një përmbledhje konsideratash të përgjithshme për dukurinë sa interesante aq dhe pak të studiuar në gjuhësinë tonë, emrat valentë në strukturat reciproke. Është një fillim për një studim të mëtejshëm, më të thelluar mbi dukurinë në fjalë.

Vlera, denduria, rëndësia gjuhësore e kësaj dukurie, reciprocitetit të shprehur me struktura ku fjalë drejtuese është një emër, evidentohet më qartë e dukshëm e ilustruar me gjuhën e përdorur nga një autor i mirënjohur elbasanas, S. Sadiku. Ky shkrimtar, i lindur në Elbasan, ka një veprimtari të gjerë publicistike-letrare. Tematika e shkrimeve dhe e tregimeve të tij është e mbushur me jetën që rrjedh rrugëve të qytetit të lashtë dhe në rrethinat e tij malore, piktoreske ku autori kaloi tëre rininë dhe pjesën më të madhe të jetës. Nuk ishte rastësi që iu drejtova kësaj literature për ta përdorur si korpus. Në të gjëllijnë e zhurmojnë aq fort marrëdhëniet ndërnjerëzore, lidhjet, ndarjet, miqësitë, dashuritë... Atje, ku njerëzit veprojnë në bashkësi, atje lind reciprociteti human.

\section{BIBLIOGRAFI}

Teubert, Wolfgang (1999): Substantivvalenz. Unveröffentlichtes Manuskript.

Welke, Klaus (1995): Wortbildung und Valenz. In: Der Ginko-Baum 13, 228-236

Zifonun, Gisela (2003b): Grammatik des Deutschen im europäischen Vergleich: Das Pronomen. 


\section{Albanon \\ Revistë kulturore}

Helbig, Gerhard (1995): Erweiterungen des Valenzmodells.

Eroms, Hans-Werner (1981): Valenz Kasus und Präpositionen.

Engel, Ulrich (1998): Deutsche Grammatik. Heidelberg.

Sadiku, Emine: Modelet ndërtimore të fjalive në gjuhën shqipe, "Hapa në universin e ligjërimit“", Tiranë, 2010.

Engel, Ulrich; Sadiku, Emine: Valenzlexikon Deutsch -Albanisch (në proces).

Fedorovna, Anna: Relationale Substantive, Münich, 2004.

Fjalori i Shqipes së Sotme, Tiranë, 1984. 